\title{
Adult cardiac surgery during the COVID-19 pandemic: A tiered patient triage guidance statement
}

Jonathan W. Haft, MD, ${ }^{\mathrm{a}}$ Pavan Atluri, MD, ${ }^{\mathrm{b}}$ Gorav Ailawadi, MD, MBA, ${ }^{\mathrm{c}}$ Daniel T. Engelman, MD, ${ }^{\mathrm{d}}$

Michael C. Grant, MD, ${ }^{\mathrm{e}}$ Ansar Hassan, MD, PhD,${ }^{\mathrm{f}}$ Jean-Francois Legare, MD, MSc, ${ }^{\mathrm{f}}$

Glenn J. R. Whitman, MD, ${ }^{\mathrm{g}}$ and Rakesh C. Arora, MD, PhD, ${ }^{\mathrm{h}}$ on behalf of The Society of Thoracic

Surgeons COVID-19 Task Force and the Workforce for Adult Cardiac and Vascular Surgery

In the setting of the current novel coronavirus pandemic, this document has been generated to provide guiding statements for the adult cardiac surgeon to consider in a rapidly evolving national landscape. Acknowledging the risk for a potentially prolonged need for cardiac surgery procedure deferral, we have created this proposed template for physicians and interdisciplinary teams to consider in protecting their patients, institution, and their highly specialized cardiac surgery team. In addition, recommendations on the transition from traditional in-person patient assessments and outpatient follow-up are provided. Lastly, we advocate that cardiac surgeons must continue to serve as leaders, experts, and relevant members of our medical community, shifting our role as necessary in this time of need. (J Thorac Cardiovasc Surg 2020;160:452-5)

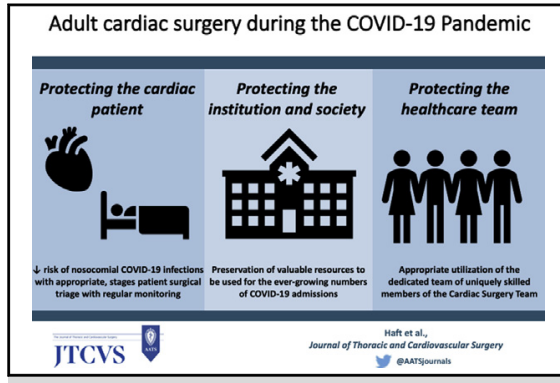

Adult cardiac surgery during the COVID-19 pandemic.

CENTRAL MESSAGE

The current COVID-19 pandemic has had profound impact on the landscape of the delivery of cardiac surgery care. The intent of this document is to provide guidance on issues pertaining to surgical case triage and monitoring and surgical team leadership in these challenging and rapidly evolving times.
From the ${ }^{\mathrm{a} D e p a r t m e n t}$ of Cardiac Surgery, University of Michigan, Ann Arbor, Mich; ${ }^{\mathrm{b}}$ Division of Cardiovascular Surgery, Department of Surgery, University of Pennsylvania, Philadelphia, Pa; ${ }^{\mathrm{c} D e p a r t m e n t ~ o f ~ S u r g e r y, ~ U n i v e r s i t y ~ o f ~ V i r g i n i a, ~ C h a r-~}$ lottesville, Va; ${ }^{\mathrm{d}}$ University of Massachusetts Medical School-Baystate, Springfield, Mass; ${ }^{e}$ Department of Anesthesiology and Critical Care Medicine, The Johns Hopkins University School of Medicine, Baltimore, Md; ${ }^{\mathrm{f}} \mathrm{New}$ Brunswick Heart Centre, Saint John, New Brunswick, Canada; ${ }^{g}$ Department of Surgery, The Johns Hopkins University School of Medicine, Baltimore, Md; ${ }^{\text {h Section of }}$ Cardiac Surgery, Department of Surgery, Max Rady College of Medicine, University of Manitoba, Winnipeg, Manitoba, Canada.

The American Association for Thoracic Surgery and The Society of Thoracic Surgeons support this document.

This article has been copublished in The Journal of Thoracic and Cardiovascular Surgery and The Annals of Thoracic Surgery.
The American Association for Thoracic Surgery requests that this article be cited as: Haft JW, Atluri P, Ailawadi G, Engelman DT, Grant MC, Hassan A, Legare J-F, Whitman GJR, Arora RC, on behalf of The Society of Thoracic Surgeons COVID-19 Task Force and the Workforce for Adult Cardiac and Vascular Surgery. Adult cardiac surgery during the COVID-19 pandemic: a tiered patient triage guidance statement. J Thorac Cardiovasc Surg. 2020;160:452-5.

Received for publication April 6, 2020; accepted for publication April 8, 2020; available ahead of print April 16, 2020.

Address for reprints: Rakesh C. Arora, MD, PhD, St. Boniface Hospital, CR3015-369 Tache Ave, Winnipeg, MB R2H2A6, Canada (E-mail: rakeshcarora@gmail.com). J Thorac Cardiovasc Surg 2020;160:452-5 $0022-5223 / \$ 36.00$

Copyright (C) 2020 by The Society of Thoracic Surgeons and the American Association for Thoracic Surgery. Published by Elsevier Inc.

https://doi.org/10.1016/j.jtcvs.2020.04.011 


\section{Abbreviations and Acronyms \\ ASD $\quad=$ atrial septal defect \\ $\mathrm{CAD}=$ coronary artery disease \\ COVID-19 $=$ novel severe acute respiratory \\ syndrome coronavirus 2 (coronavirus disease 2019) \\ HCM = hypertrophic cardiomyopathy \\ MR = mitral regurgitation \\ PFO = patent foramen ovale \\ $\mathrm{VAD} \quad=$ ventricular assist device}

should avoid close contact with others. This specifically includes patients aged older than 65 years and those with lung or heart conditions, diabetes, and obesity. This obviously represents most of the population that requires cardiac surgery.

The intent of this document is to provide guidance to the adult cardiac surgery perioperative community regarding management of patients considered or scheduled for surgical procedures in the context of the current pandemic. Specifically, contained within is a proposed template for physicians and interdisciplinary teams to consider and adapt to the unique aspects of each patient in the specific context of the prevalence of COVID-19 at the medical center where they are being treated. The purpose of postponing or cancelling cardiac operations is based on these principles:

Novel coronavirus severe acute respiratory syndrome coronavirus 2 (SARS CoV-2), or coronavirus disease 2019 (COVID-19), has been declared a worldwide pandemic by the World Health Organization. At the time of writing this document, more than 1,200,000 cases have been reported worldwide and more than 320,000 in the United States alone. ${ }^{1}$ There is substantial regional variation within the United States, particularly extreme in the populous northeast. $^{2}$

Dependence on hospital infrastructure to manage the outbreak is variable and difficult to predict. Mandatory quarantines are present in many states, and the Centers for Disease Control and Prevention has stated that certain individuals are at higher risk in the setting of the pandemic and
1. Protecting the cardiac patient: As our hospitals become increasingly populated with patients with suspected or confirmed COVID-19, exposing cardiac patients to the hospital environment will potentially increase their risk of nosocomial infection. It is uncertain how acquisition of COVID-19 in the perioperative phase will impact morbidity and mortality.

2. Protecting the institution and society at large: Reducing the number of cardiac surgical procedures will result in the preservation of valuable resources that will allow for intensive care unit beds, mechanical ventilators, circuitry for extracorporeal membrane oxygenation, pharmaceuticals, personal protective equipment, and health

TABLE 1. Guiding statement for patient triage during tier $1(0 \%-30 \%$ inpatient COVID-19 load, mild reduction in operative capacity)

\begin{tabular}{|c|c|}
\hline \multicolumn{2}{|l|}{ Tier 1} \\
\hline Essential services & Deferred \\
\hline $\begin{array}{l}\text { - All inpatients waiting for surgery, including emergency services (ie, ascending } \\
\text { aortic dissections, acute coronary syndromes, acute valvular endocarditis, and } \\
\text { heart failure patients awaiting heart transplant or VAD) } \\
\text { - Outpatients who are at greatest risk of adverse event, examples of which include: } \\
\text { Symptomatic critical aortic stenosis } \\
\text { - CAD } \\
\text { - Severe CAD with large territory of myocardium at risk } \\
\text { - Asymptomatic CAD with reduced systolic function } \\
\text { - Progressive angina } \\
\text { Cardiac tumors at risk of obstruction or embolization } \\
\text { Aortic aneurysm at risk based on size and familial association } \\
\text { Patients with correctable, anatomic causes of heart failure (valvular } \\
\text { or myocardial; ie, HCM, adult congenital) } \\
\text { End-stage heart failure patients in evaluation for mechanical assist } \\
\text { devices who are inotrope dependent }\end{array}$ & $\begin{array}{l}\text { - Asymptomatic outpatients } \\
\text { - Truly elective intervention could include: } \\
\circ \text { Asymptomatic or minimally symptomatic severe MR } \\
\circ \text { ASD or PFO surgery, or both } \\
\circ \text { Asymptomatic aneurysm with demonstrated stable size } \\
\circ \text { Isolated arrhythmia procedures }\end{array}$ \\
\hline $\begin{array}{l}\text { Programs are encouraged to adopt a mechanism by which patients can be screen } \\
\text { those having increased symptoms or progression of disease } \\
\text { Transcatheter interventions will follow the same recommendations } \\
\text { Alternative percutaneous therapies with rapid discharge from the hospital should } \\
\text { Thoracic organ transplant guidance is provided by the United Network for Orgar }\end{array}$ & $\begin{array}{l}\text { regularly in order to identify } \\
\text { considered } \\
\text { aring }\end{array}$ \\
\hline
\end{tabular}


TABLE 2. Guiding statement for patient triage during tier $2(30 \%-60 \%$ inpatient COVID-19 load, moderate reduction in operative capacity)

Tier 2

Essential services $\quad$ Deferred

- All inpatients waiting for surgery, including emergency services

- Outpatients with progressive symptoms who have demonstrated

- Asymptomatic outpatients and patients with anatomy and failure to medical management Symptomatic CAD

- Asymptomatic CAD with impaired systolic function

- Programs are encouraged to adopt a mechanism by which patients can be screened regularly to identify those having increased symptoms or progression of disease

- Transcatheter interventions will follow the same recommendations

- Alternative percutaneous therapies with rapid discharge from the hospital should be considered

- Thoracic organ transplant guidance is provided by the United Network for Organ Sharing

$C A D$, Coronary artery disease.

care workers with advanced skills to be used for the ever growing numbers of COVID-19 admissions.

3. Protecting the health care team: Cardiac surgery requires a relatively small dedicated team of uniquely skilled individuals, including cardiac operating room scrub and circulators, perfusionists, cardiac anesthesiologists, and perioperative caregivers. Using these individuals for potentially nonessential operations may increase their chances of COVID-19 exposure, threatening their availability for future more urgent procedures.

There is obviously a balance of risk, as patients with significant cardiovascular disease have their definitive treatment delayed vs increasing the likelihood of acquiring a nosocomial COVID-19 infection and its consequences. The factors resulting in delaying a cardiac surgical procedure are multifold. Blood products are in short supply because volunteer donation rates are substantially reduced under the advisory of avoiding close contact. Each cardiac surgical procedure will necessarily consume increasingly scarce resources (inpatient space, human resources, personal protective equipment, etc) that might delay or prevent treatment of a patient suffering from the sequela of a COVID-19 infection. Lastly, there is an increasing awareness of the importance of preventing infections of the health care team by patients who may be asymptomatic carriers.
Screening of asymptomatic patients should be determined based on institutional practice.

At a time when our nation's health care resources are insufficient to meet this unprecedented demand, prioritizing needs in the hopes of maximizing lives saved is necessary. Although delaying definitive treatment of cardiovascular disorders may present risk to certain individuals, countless others will be afforded life-saving resources necessary to overcome the most threatening manifestation of this illness (Tables 1-4).

Given that the duration of COVID-19 burden in our hospitals is presently unknown, it is foreseeable that reduction in cardiac surgery capacity may be impacted for several months or longer. For patients whose cardiac surgical procedures are being delayed and in whom alternative therapies are not deemed appropriate, programs are encouraged to develop an orchestrated follow-up mechanism for regular communication (ie, 1- to 2-week intervals) to monitor for progression of symptoms by telephone conference or video conference.

Timely reprioritization can be considered given the dynamic nature of some patients with cardiovascular disease. Each individual patient should be given careful consideration, weighing risks and potential therapeutic alternatives, including medical treatment, catheter-based

TABLE 3. Guiding statement for patient triage during tier $3(60 \%-80 \%$ inpatient COVID-19 load, severe reduction in operative capacity)

\begin{tabular}{|c|c|}
\hline \multicolumn{2}{|c|}{ Tier 3} \\
\hline Essential services & Deferred \\
\hline $\begin{array}{l}\text { - All inpatients who cannot be discharged safely without surgical } \\
\text { intervention/correction, including emergency services }\end{array}$ & $\begin{array}{l}\text { - All patients who are outpatients } \\
\text { - Patients deteriorating while waiting would need to meet criteria } \\
\text { for admission before consideration for surgery }\end{array}$ \\
\hline $\begin{array}{l}\text { Programs are encouraged to adopt a mechanism by which patie } \\
\text { increased symptoms or progression of disease } \\
\text { - Transcatheter interventions will follow the same recommendati } \\
\text { Alternative percutaneous therapies with rapid discharge from th } \\
\text { - Thoracic organ transplant guidance is provided by the United N }\end{array}$ & $\begin{array}{l}\text { ed regularly to identify those having } \\
\text { be considered } \\
\text { n Sharing }\end{array}$ \\
\hline
\end{tabular}


TABLE 4. Guiding statement for patient triage during stage 4 ( $>80 \%$ inpatient COVID-19 load, minimal operative capacity)

\begin{tabular}{ll}
\hline Essential services & Tier 4 \\
\hline - Only emergency services based on resource availability & - All inpatients judged to be stable and capable of waiting \\
- With extreme reductions in operative capacity, ability (or inability) to perform surgery should be evaluated in the case of emergent cases, \\
and alternate arrangements at peer institutions with potential capacity should be sought \\
Thoracic organ transplant guidance is provided by the United Network for Organ Sharing
\end{tabular}

therapy, or even a recommendation to transfer to a center with lower COVID-19 penetrance and more available resources. Under these circumstances, it is important to recognize that regional competitors must now become collaborators.

Programs are encouraged to limit in-person clinic evaluations and testing for appropriately selected patients who can be safely deferred, understanding the uncertainty of the pandemic duration. Telephone and video visits should be incorporated for both new patient evaluations and postoperative assessments. As the morphology of the typical cardiac surgery practice evolves, program leaders must determine how to effective and safely "skeletonize" hospital and office staffing, including surgeons, advance practice providers, and administrative and clerical personnel, and in some cases, creating opportunities for team members to work from home. There should also be specific consideration to accommodate individuals at higher risk of COVID-19 because of advanced age or the presence of underlying health conditions.

As our surgical volume declines over the next several months, it is essential that the cardiothoracic surgical community maintains its commitment to the health and safety of its patients. While hospitals shift their focus to medical management of this outbreak, cardiac surgeons may feel uncertainty about their role. In addition to our expertise in the care of advanced cardiac disease, there will also likely be an expanded need for the use of extracorporeal membrane oxygenation, requiring cardiac surgical direction and partnership with the Extracorporeal Life Support Organization. ${ }^{3}$ We must continue to serve as leaders, experts, and members of our medical community, willing to play any role necessary in this time of need.

The authors would like to acknowledge the work of the Canadian Society of Cardiac Surgeon Board of Directors that shared an earlier draft of their national guidance documents with this team of authors.

\section{References}

1. Coronavirus COVID-19 Global Cases by the Center for Systems Science and Engineering (CSSE) at Johns Hopkins University (JHU). Available at: https:// gisanddata.maps.arcgis.com/apps/opsdashboard/index.html\#/bda7594740fd4029 9423467b48e9ecf6. Accessed April 6, 2020.

2. The New York Times. Coronavirus in the U.S.: Latest Map and Case Count by The New York Times. Available at: https://www.nytimes.com/interactive/2020/us/ coronavirus-us-cases. html action $=$ click $\&$ module $=$ Spotlight $\&$ pgtype $=$ Homepag e\#states. Accessed April 6, 2020

3. Extracorporeal Life Support Organization (ELSO). ELSO Guidance Document: ECMO for COVID-19 Patients with Severe Cardiopulmonary Failure; 2020. Available at: https://www.elso.org/Portals/0/Files/pdf/ECMO $\% 20$ for $\% 20$ COVID $\% 20$ 19\%20Guidance\%20Document.Final\%2003.24.2020.pdf. Accessed April 6, 2020. 